\title{
Relationship between the achieved blood pressure and the incidence of cardiovascular events in Japanese hypertensive patients with complications: a sub-analysis of the CASE-J trial
}

\author{
Toshio Ogihara ${ }^{1}$, Takao Saruta ${ }^{2}$, Hiromi Rakugi ${ }^{3}$, Akira Fujimoto $^{4}$, Kenji Ueshima ${ }^{4}$, Shinji Yasuno ${ }^{4}$, Koji Oba $^{4}$, \\ Kazuo Takeda ${ }^{5}$, Jitsuo Higaki ${ }^{6}$ and Kazuwa Nakao ${ }^{4,7}$, on behalf of the CASE-J trial Group
}

Various guidelines for hypertension specify that the target blood pressure (BP) should be below $140 / 90 \mathrm{~mm} \mathrm{Hg}$ and that strict control is recommended for patients with cardiovascular risk factors. We examined the relationship between the achieved BP and the incidence of cardiovascular events in hypertensive patients with complications as a sub-analysis of the Candesartan Antihypertensive Survival Evaluation in Japan (CASE-J) trial. A total of $\mathbf{4 7 0 3}$ patients were evaluated for efficacy in the CASE-J trial. In this sub-analysis, 4553 patients had at least one follow-up visit without any cardiovascular events. We examined the relationship between the achieved BP and cardiovascular events in hypertensive patients with type II diabetes mellitus (DM), chronic kidney disease (CKD) or left ventricular hypertrophy (LVH) at baseline. Possible baseline confounders were adjusted by using the multiple Cox regression model. A higher achieved BP was associated with an increased risk of cardiovascular events in hypertensive patients with complications (DM, CKD or LVH). In patients with LVH, who achieved systolic/diastolic BP (SBP/DBP) $<130 / 75-79 \mathrm{~mm} \mathrm{Hg}$, the risk of cardiovascular events was reduced to the same level of SBP/DBP $<130 / 75-79 \mathrm{~mm} \mathrm{Hg}$ in those without LVH. However, the risks of cardiovascular events in patients with DM or CKD, who achieved SBP/DBP $<130 / 75-79 \mathrm{~mm} \mathrm{Hg}$, were still significantly higher than in those without DM or CKD. In conclusion, this study extended the significance of BP control in hypertensive patients especially with complications. Further investigation in a large-scale clinical trial is needed to determine the optimal target BP for LVH patients.

Hypertension Research (2009) 32, 248-254; doi:10.1038/hr.2008.34

Keywords: CASE-J; CKD; diabetes; LVH

\section{INTRODUCTION}

The prognosis of patients with hypertension does not only depend on the blood pressure (BP) but also on other cardiovascular risk factors (smoking, diabetes, advanced age and family history) and comorbidities, such as hypertensive organ damage and cardiovascular disease. In particular, hypertensive patients with diabetes mellitus (DM) have been reported to have a high risk of suffering from cardiovascular events, ${ }^{1-3}$ and aggressive antihypertensive therapy is recommended for such patients in several guidelines. ${ }^{4-6}$ Control of hypertension is also required to prevent the progression of renal impairment. $^{7}$ Thus, strict BP control is essential for hypertensive patients with $\mathrm{DM}$ and/or chronic kidney disease (CKD). Cardiac hypertrophy is often associated with other cardiovascular diseases, such as hypertension and ischemic heart disease, and is one of the independent risk factors that influence the prognosis of hypertensive patients. Owing to cardiac events and heart failure, both mortality and morbidity are increased in hypertensive patients with left ventricular hypertrophy (LVH). ${ }^{8}$

We recently performed the Candesartan Antihypertensive Survival Evaluation in Japan (CASE-J trial), which was a large-scale clinical trial in high-risk hypertensive patients that compared an angiotensin II receptor blocker (candesartan cilexetil) and a calcium channel blocker (amlodipine besylate) with respect to the prevention of cardiovascular events. ${ }^{9}$ The incidence of cardiovascular events in the CASE-J trial occurred relatively lower compared with previous similar studies, such as the Valsartan Antihypertensive Long-term Use Evaluation trial, ${ }^{10}$ and the CASE-J trial showed no significant difference between the candesartan and amlodipine groups. ${ }^{11}$ The achieved BP in

${ }^{1}$ Osaka General Medical Center, Osaka, Japan; ${ }^{2}$ Keio University Graduate School of Medicine, Tokyo, Japan; ${ }^{3}$ Department of Geriatric Medicine, Osaka University Graduate School of Medicine, Suita, Japan; ${ }^{4}$ EBM Research Center, Kyoto University Graduate School of Medicine, Kyoto, Japan; ${ }^{5}$ Kyoto Industrial Health Association, Kyoto, Japan; ${ }^{6}$ Department of Integrated Medicine and Informatics, Ehime University Medical School, Ehime, Japan and ${ }^{7}$ Department of Medicine and Clinical Science, Kyoto University Graduate School of Medicine, Kyoto, Japan

Correspondence: Professor T Ogihara, Osaka General Medical Center, 3-1-56, Bandai-higashi, Sumiyoshi-ku, Osaka 558-8558, Japan.

E-mail: ogiharat@opho.jp

Received 31 August 2008; revised 30 November 2008; accepted 15 December 2008 
the CASE-J trial was lower than that in large-scale clinical trials reported earlier, suggesting that the strict BP control overcame the differences of pharmacological action between the two antihypertensive agents.

The CASE-J trial provides us with the opportunity to verify the significance of BP control in high-risk hypertensive patients. In this study, we performed a sub-analysis of the CASE-J trial to examine the relationship between the achieved $\mathrm{BP}$ and the incidence of cardiovascular events in patients with DM, CKD or LVH.

\section{METHODS}

\section{Study population and treatment}

The original CASE-J trial was a prospective randomized open-label blinded-end point study. Details of the study protocol and the main results have been reported earlier. ${ }^{9,11}$ The subjects of the CASE-J trial were high-risk patients with essential hypertension, who had at least one of the following cardiovascular risk factors: (1) sitting systolic BP (SBP) $\geqslant 180 \mathrm{~mm} \mathrm{Hg}$ or diastolic BP (DBP) $\geqslant 110 \mathrm{~mm} \mathrm{Hg}$; (2) type II DM; (3) a history of stroke or transient ischemic attacks; (4) LVH, angina pectoris or a history of myocardial infarction; (5) proteinuria or renal dysfunction (serum creatinine $>1.3 \mathrm{mg}$ per $100 \mathrm{ml}$ ); or (6) peripheral arterial disease (Fontaine classification grade II or higher). After randomization, the enrolled patients were given one of the two following medications to achieve the targets for control of BP according to the guidelines developed by the Japanese Society of Hypertension (JSH): $:^{12}<60$ years old, SBP/DBP < 130/85 mm Hg; 60s, SBP/DBP < 140/90 mm Hg; 70s, SBP/DBP $<150 / 90 \mathrm{~mm} \mathrm{Hg}$; and 80 s, SBP/DBP $<160 / 90 \mathrm{~mm} \mathrm{Hg}$. The one of the medication given was candesartan administered orally at a dose of 4-8 $\mathrm{mg} \mathrm{day}^{-1}$. When the BP did not reach the targets for the control of BP, the dose was increased up to $12 \mathrm{mg} \mathrm{day}^{-1}$. The other medication was amlodipine administered orally at a dose of $2.5-5 \mathrm{mg} \mathrm{day}^{-1}$ and increased up to $10 \mathrm{mg} \mathrm{day}^{-1}$ when necessary. Once a patient was given the assigned medication, the use of other angiotensin II receptor blockers, calcium channel blockers and all angiotensinconverting enzyme inhibitors was prohibited. Patients already being treated with diuretics, $\alpha$-blockers, $\beta$-blockers or $\alpha$ - and $\beta$-blockers before enrollment were allowed to continue taking these medications.

\section{End point and event evaluation criteria}

The primary outcome for this sub-analysis was defined as any of the following cardiovascular events (whichever occurred first): sudden death; stroke/transient ischemic attack; acute myocardial infarction, heart failure or angina pectoris; doubling of serum creatinine or an increase to $\geqslant 4.0 \mathrm{mg}$ per $100 \mathrm{ml}$ or endstage renal disease; dissecting aortic aneurysm; and occlusive peripheral arterial disease.

Occurrence of each event was independently judged by an independent event evaluation committee. The summary of the definition was as follows: (1) sudden death-unexpected abrupt death within $24 \mathrm{~h}$ without external cause; (2) cerebrovascular event-new onset or recurrence of stroke, transient ischemic attack (local neurological symptoms completely resolve within $24 \mathrm{~h}$ and symptoms develop rapidly) and other cases of stroke that are not classifiable; (3) cardiac event-new onset or recurrence of acute myocardial infarction according to the diagnostic criteria of World Health Organization (WHO)/Monica Project, new onset, exacerbation or recurrence of heart failure assessed by the New York Heart Association (NYHA) classification or angina pectoris; (4) renal event-doubling of serum creatinine (this is not considered as a renal event if the level is $\leqslant 2.0 \mathrm{mg}$ per $100 \mathrm{ml}$ ), serum creatinine of $\geqslant 4.0 \mathrm{mg}$ per $100 \mathrm{ml}$ or end-stage renal disease (requiring dialysis or renal transplantation); (5) vascular event-new onset or exacerbation of dissecting aneurysm of aorta or arteriosclerotic peripheral arterial disease; and (6) other cardiovascular events-when the physician reported that his/her patient possibly had a cardiovascular event which did not meet the above criteria, the event evaluation committee assessed the occurrence individually.

In this sub-analysis, CKD was defined as creatinine clearance $<60 \mathrm{ml} \mathrm{min}^{-1}$, which was calculated by the Cockroft-Gault formulae ${ }^{13}$ and/or proteinuria at baseline, whereas LVH was defined as a left ventricular posterior wall or interventricular septal thickness $\geqslant 12 \mathrm{~mm}$ on echocardiography or Sv1+Rv5 $\geqslant 35 \mathrm{~mm}$ on electrocardiography.

\section{Statistical methods}

The association between the achieved BP and the occurrence of cardiovascular events was analyzed in patients who made at least one follow-up visit without any cardiovascular events. The achieved BP was defined as the BP measured at the final study visit. In patients who experienced a cardiovascular event, the achieved BP was defined as that measured within 6 months before the event occurred. The achieved SBP and DBP were classified into five levels (SBP: <130, 130-139, 140-149, 150-159 and $\geqslant 160 \mathrm{~mm} \mathrm{Hg}$; DBP: <75, 75-79, 80-84, 85-89 and $\geqslant 90 \mathrm{~mm} \mathrm{Hg}$ ).

We calculated the crude incidence rates (per 1000 person-years) of cardiovascular events in the subsets of patients with DM, CKD or LVH. Adjusted hazard ratios (HRs) and 95\% confidence intervals (CIs) were calculated by the multiple Cox proportional hazard model with adjustment for patient characteristics (sex, age, body mass index, treatment group, antihypertensive treatment before starting the CASE-J trial, smoking, drinking, DM, hyperlipidemia, severe hypertension, a history of cerebrovascular events, a history of ischemic heart disease, LVH and renal dysfunction) by setting a reference category at $<130 \mathrm{~mm} \mathrm{Hg}$ for SBP and at $75-79 \mathrm{~mm} \mathrm{Hg}$ for DBP in the subset of patients without DM, CKD or LVH. The interaction between the status of complication and the achieved $\mathrm{BP}$ as a continuous variable was also assessed using the interaction term in the multiple Cox proportional hazard model. Statistical tests were two-sided and the level of significance was set at $P \leqslant 0.05$. All statistical analyses were performed using SAS version 9.1 (SAS Institute, Cary, NC, USA).

\section{RESULTS}

\section{Demographic profile}

A total of 4728 patients with essential hypertension were enrolled in the CASE-J trial. Among them, 4703 patients were evaluated for efficacy, comprising 2354 candesartan-treated patients and 2349 amlodipine-treated patients. The mean follow-up time was 3.2 years and $2.9 \%$ of patients were lost to follow-up. In this sub-analysis, 4553 patients (2278 in the candesartan group and 2275 in the amlodipine group) had at least one follow-up visit without any cardiovascular events. The baseline characteristics of the subjects are shown in Table 1. The mean SBP/DBP at enrollment was $162.7 / 91.6 \mathrm{~mm} \mathrm{Hg}$ and controlled to $136.2 / 77.5 \mathrm{~mm} \mathrm{Hg}$ after 3 years. Since DM, LVH or renal dysfunction is one of the entry criteria, the proportions of other each baseline characteristic were higher compared with the general population in patients without complications.

\section{Relationship between the achieved BP and the incidence of cardiovascular events}

The event number and crude incidence rate of each achieved BP level with or without any complication (DM, LVH or CKD) are shown in the first row of Table 2. About $85 \%$ of patients in the CASE-J trial had DM, LVH or CKD at baseline. Figure 1 depicts the adjusted relative risk of BP levels compared with $\mathrm{SBP}<130 \mathrm{~mm} \mathrm{Hg}$ and DBP $75-79 \mathrm{~mm} \mathrm{Hg}$ only in the subgroup with any of the complications. The incidence of cardiovascular events tended to increase when the achieved SBP exceeded $130 \mathrm{~mm} \mathrm{Hg}$ and increased significantly when the achieved SBP exceeded $140 \mathrm{~mm} \mathrm{Hg}(\mathrm{HR}=1.82$, 95\% $\mathrm{CI}=1.19$ 2.77, $P=0.006$; Figure 1a) compared with SBP $<130 \mathrm{~mm} \mathrm{Hg}$. The incidence of cardiovascular events increased significantly when the achieved DBP exceeded $85 \mathrm{~mm} \mathrm{Hg}(\mathrm{HR}=2.61,95 \% \mathrm{CI}=1.55-4.39$, $P<0.001$; Figure 1b) compared with DBP $75-79 \mathrm{~mm} \mathrm{Hg}$.

The crude incidence of cardiovascular events stratified by the achieved BP levels and the status of baseline risks are also shown in Table 2. With regard to DM, the hazards of all achieved SBP levels in patients with DM were significantly higher compared with those of the achieved SBP $<130 \mathrm{~mm} \mathrm{Hg}$ in patients without DM (Figure 2a). 


\begin{tabular}{|c|c|c|c|c|c|c|c|}
\hline & \multirow[b]{2}{*}{ All } & \multicolumn{2}{|c|}{ DM status } & \multicolumn{2}{|c|}{ LVH status } & \multicolumn{2}{|c|}{ CKD status ( $C c r<60$ or UP) } \\
\hline & & Non-DM & $D M$ & Non-LVH & $\mathrm{LVH}$ & Non-CKD & $C K D$ \\
\hline Age (years) & $63.9 \pm 10.5$ & $63.8 \pm 11.1$ & $64.0 \pm 9.6$ & $64.3 \pm 10.3$ & $63.1 \pm 10.8$ & $60.1 \pm 9.5$ & $68.3 \pm 9.7$ \\
\hline Candesartan & $976(49.9)$ & $1302(50.2)$ & $976(49.9)$ & $1509(50.4)$ & $769(49.4)$ & $1206(48.8)$ & $1072(51.6)$ \\
\hline Male (\%) & $2517(55.3)$ & $1099(56.1)$ & $1418(54.6)$ & $1519(50.7)$ & $998(64.1)$ & $1536(62.1)$ & $981(47.2)$ \\
\hline Type II diabetes mellitus (\%) & $1958(43.0)$ & $0(0.0)$ & $1958(100.0)$ & $1499(50.1)$ & $459(29.5)$ & $1125(45.5)$ & $833(40.1)$ \\
\hline Cerebrovascular history ${ }^{\mathrm{a}}(\%)$ & $464(10.2)$ & $339(13.1)$ & $125(6.4)$ & 369 (12.3) & $95(6.1)$ & $197(8.0)$ & 267 (12.8) \\
\hline $\mathrm{LVH}^{\mathrm{a}}(\%)$ & $1558(34.2)$ & $1099(42.4)$ & $459(23.4)$ & $0(0.0)$ & $1558(100.0)$ & $932(37.7)$ & $626(30.1)$ \\
\hline Ischemic heart disease history ${ }^{\mathrm{a}}(\%)$ & $587(12.9)$ & $203(10.4)$ & $384(14.8)$ & $413(13.8)$ & $174(11.2)$ & $335(13.5)$ & $252(12.1)$ \\
\hline Renal dysfunction ${ }^{\mathrm{a}}(\%)$ & $1090(23.9)$ & $659(25.4)$ & $431(22.0)$ & $791(26.4)$ & $299(19.2)$ & $27(1.1)$ & $1063(51.1)$ \\
\hline Vascular disease (\%) & $52(1.1)$ & $36(1.4)$ & $16(0.8)$ & $43(1.4)$ & $9(0.6)$ & $25(1.0)$ & $27(1.3)$ \\
\hline Current non-alcohol (\%) & $2391(52.5)$ & $1319(50.8)$ & $1072(54.8)$ & $1681(56.1)$ & $710(45.6)$ & $1107(44.8)$ & $1284(61.8)$ \\
\hline \multicolumn{8}{|l|}{$S B P(m m H g)$} \\
\hline Baseline & $162.7 \pm 14.1$ & $164.9 \pm 14.8$ & $159.8 \pm 12.7$ & $163.3 \pm 14.2$ & $161.4 \pm 12.2$ & $161.7 \pm 14.8$ & $163.8 \pm 13.3$ \\
\hline During follow-up ${ }^{b}$ & $136.2 \pm 13.6$ & $135.4 \pm 12.9$ & $137.4 \pm 14.4$ & $136.3 \pm 13.4$ & $136.1 \pm 14.1$ & $135.7 \pm 13.3$ & $136.9 \pm 13.9$ \\
\hline \multicolumn{8}{|l|}{$D B P(m m ~ H g)$} \\
\hline Baseline & $91.6 \pm 11.2$ & $94.1 \pm 11.3$ & $88.3 \pm 10.1$ & $91.7 \pm 11.4$ & $91.5 \pm 10.7$ & $92.6 \pm 11.1$ & $90.4 \pm 11.1$ \\
\hline During follow-up ${ }^{b}$ & $77.5 \pm 9.8$ & $78.1 \pm 9.4$ & $76.7 \pm 10.2$ & $77.2 \pm 9.8$ & $78.1 \pm 9.8$ & $78.5 \pm 9.7$ & $76.3 \pm 9.7$ \\
\hline
\end{tabular}

Abbreviations: CASE-J, Candesartan Antihypertensive Survival Evaluation in Japan; Ccr, creatinine clearance; CKD, chronic kidney disease; Cl, confidence interval; DBP, diastolic blood pressure; DM, diabetes mellitus; HR, hazard ratio; LVH, left ventricular hypertrophy; SBP, systolic blood pressure; UP, urinary proteinuria.

*Data are shown as the mean \pm s.d. or $n(\%)$ in each category.

a Severe hypertension (blood pressure $\geqslant 180$ and/or $\geqslant 110 \mathrm{~mm} \mathrm{Hg}$ ), cerebrovascular history (a history of stroke or transient ischemic attack), ischemic heart disease history (angina pectoris or a

history of myocardial infarction), Renal dysfunction (proteinuria or serum creatinine $\geqslant 1.3 \mathrm{mg} \mathrm{dl}^{-1}$ ).

bMean achieved blood pressure.

Although the lower achieved SBP positively associated with the magnitude of risk reduction for both hypertensive patients with and without DM, the slope in patients without DM was steeper than that in patients with DM in SBP (interaction $P=0.019$ ). The patients with SBP $130-139 \mathrm{~mm} \mathrm{Hg}$ without DM achieved almost same risk as those with $\mathrm{SBP}<130 \mathrm{~mm} \mathrm{Hg}(\mathrm{HR}=1.05,95 \% \mathrm{CI}=0.56-1.97, P=0.877)$, whereas the patients with DM still showed a higher risk of cardiovascular events, even in patients who achieved SBP $<130 \mathrm{~mm} \mathrm{Hg}$ $(\mathrm{HR}=2.31,95 \% \mathrm{CI}=1.24-4.33, P=0.009)$. Figure $2 \mathrm{~b}$ shows the increased risk of cardiovascular events at higher achieved DBP in parallel and there was no interaction between patients with and without DM in DBP (interaction $P=0.687$ ).

Figure 3 shows the adjusted HRs in patients with/without LVH. The higher achieved SBP or DBP was associated with an increased risk of cardiovascular events. In detail, the HR of LVH patients who achieved SBP $140-149 \mathrm{~mm} \mathrm{Hg}(\mathrm{HR}=2.51,95 \% \mathrm{CI}=1.45-4.35, P=0.001)$ was almost the same as that of non-LVH patients with the achieved SBP of $150-159 \mathrm{~mm} \mathrm{Hg}(\mathrm{HR}=2.61,95 \% \mathrm{CI}=1.50-4.56, P<0.001)$ compared with the reference. A significant interaction was shown between the status of $\mathrm{LVH}$ and the achieved DBP (interaction $P=0.007$ ). In patients with $\mathrm{LVH}$, who achieved SBP $<130 \mathrm{~mm} \mathrm{Hg}$ or DBP $75-79 \mathrm{~mm} \mathrm{Hg}$, the risks of cardiovascular events were reduced to a reference level $(\mathrm{HR}=0.76,95 \% \mathrm{CI}=0.38-1.51, P=0.426$ for $\mathrm{SBP}$ $130 \mathrm{~mm} \mathrm{Hg}$ with $\mathrm{LVH} ; \mathrm{HR}=0.87,95 \% \mathrm{CI}=0.36-2.07, P=0.750$ for DBP 75-79 $\mathrm{mm} \mathrm{Hg}$ with LVH).
In hypertensive patients with $\mathrm{CKD}$, the increased risk of cardiovascular events was associated with the higher SBP and DBP (Figure 4). Similar to DM, patients with CKD still showed a higher risk of cardiovascular events, even in patients who achieved SBP $<130 \mathrm{~mm} \mathrm{Hg}(\mathrm{HR}=2.86,95 \% \mathrm{CI}=1.47-5.58, P=0.002)$ and $\mathrm{DBP}$ $<75 \mathrm{~mm} \mathrm{Hg}(\mathrm{HR}=4.64,95 \% \mathrm{CI}=1.99-10.80, P<0.001)$, compared with those without CKD. There was significant interaction between the status of CKD and of the achieved SBP and DBP.

\section{DISCUSSION}

This study verified that strict BP control leads to risk reduction of cardiovascular events in high-risk hypertensive patients with DM or $\mathrm{CKD}$, and is the first to show that risk reduction was also observed in patients with LVH. Interestingly, the adjusted HR indicated that the risk of cardiovascular events increased gradually following a linear regression curve when SBP exceeded $130 \mathrm{~mm} \mathrm{Hg}$ and DBP exceeded $80 \mathrm{~mm} \mathrm{Hg}$ in hypertensive patients with these risk factors. In the group without complications, however, the adjusted HR for cardiovascular events increased similar to the report by Port et al., ${ }^{14}$ with the threshold being 140-150/85 $\mathrm{mm} \mathrm{Hg}$.

In the Hypertension Optimal Treatment trial, the optimal target BP for prevention of cardiovascular events was analyzed in hypertensive patients with DM. This analysis revealed that the incidence of cardiovascular events was significantly lower in the group with the achieved DBP set at $\leqslant 80 \mathrm{~mm} \mathrm{Hg}$ than those with the achieved DBP 
Table 2 Event number and crude incidence rate for each subgroup

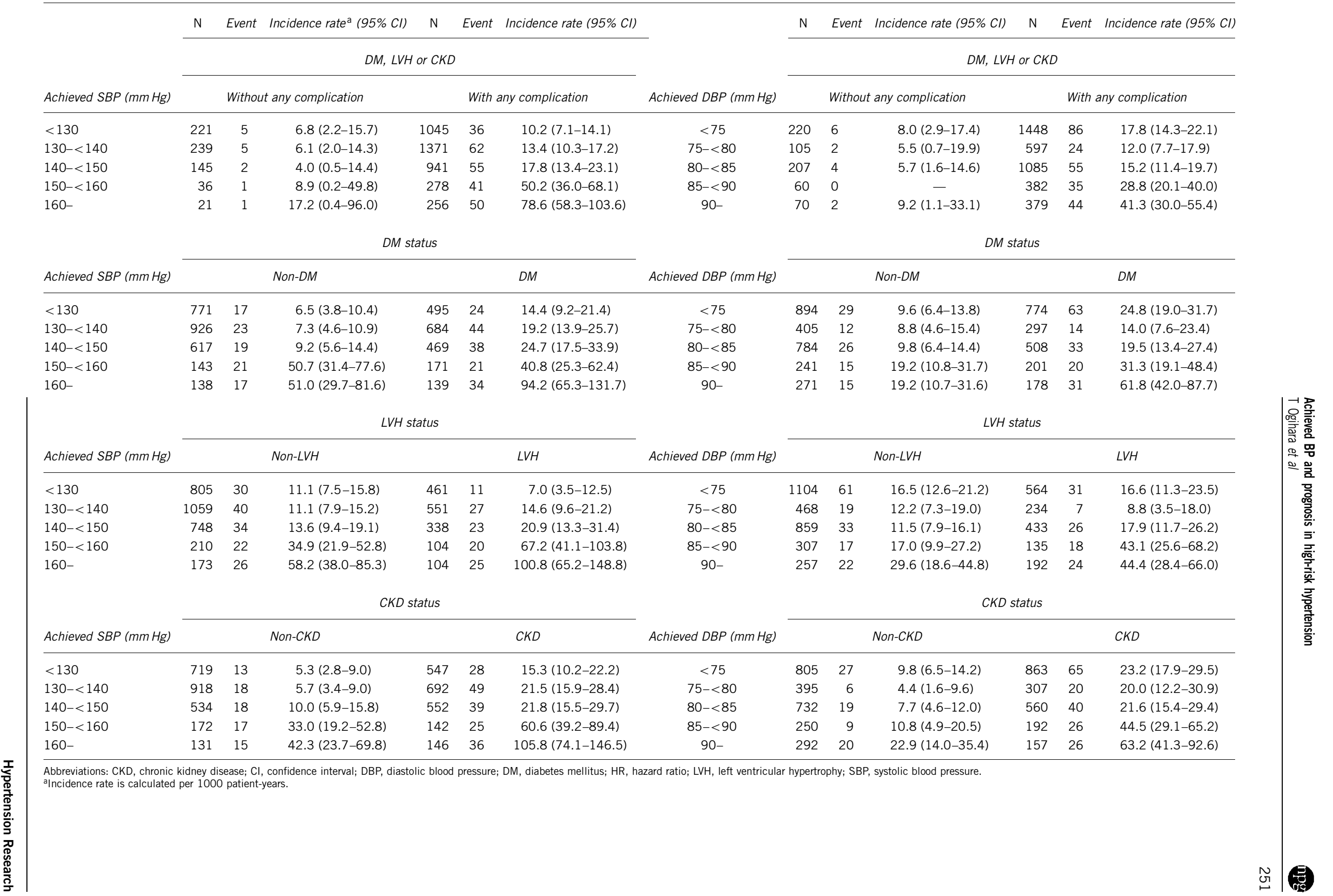




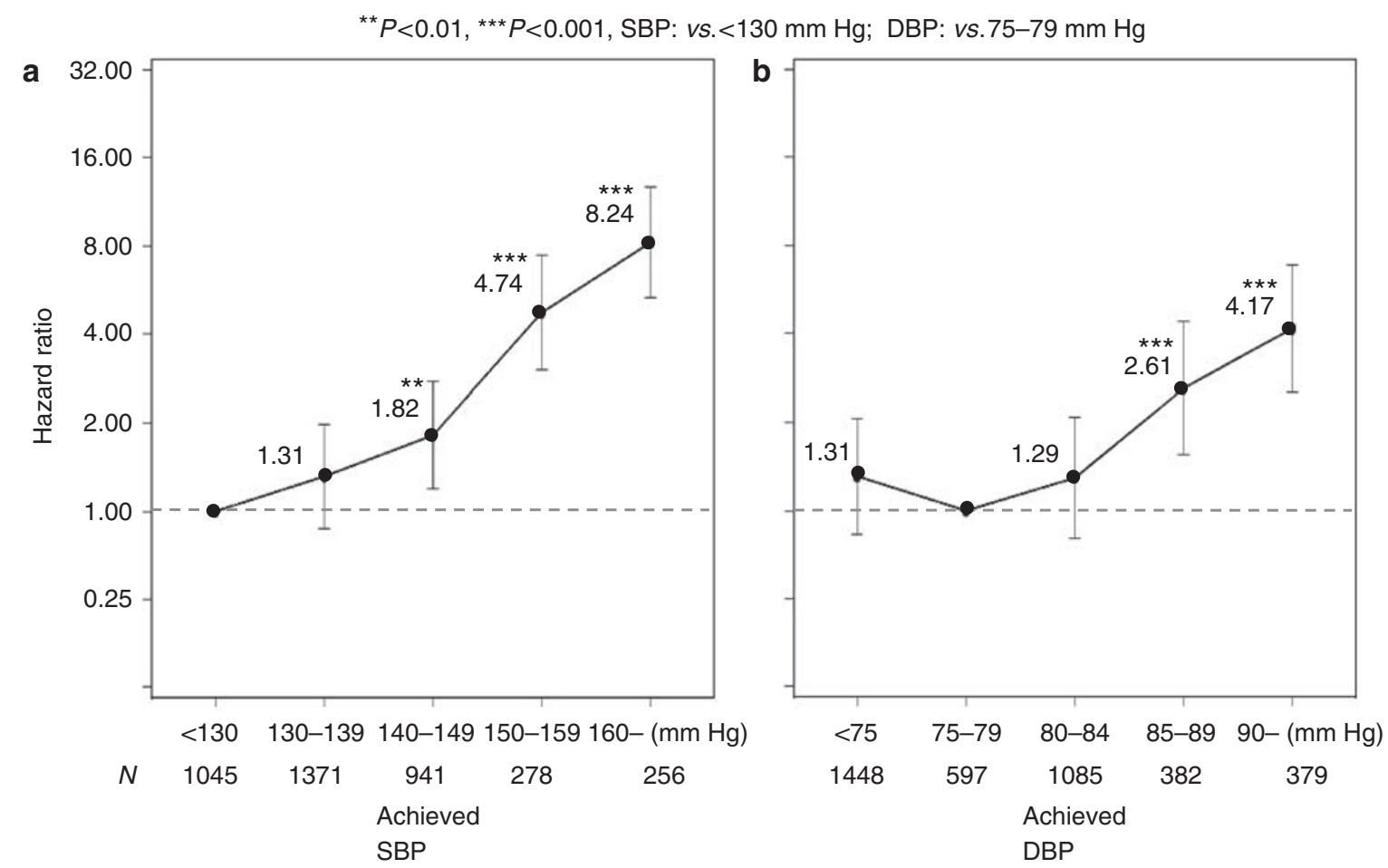

Figure 1 Adjusted relative risk of cardiovascular events and achieved BP in patients with any of the complications (DM, LVH or CKD). (a) The relationship between cardiovascular events and the achieved SBP and (b) the achieved DBP. A reference category was set at $<130 \mathrm{~mm} \mathrm{Hg}$ for SBP and at $75-79 \mathrm{~mm} \mathrm{Hg}$ for DBP.
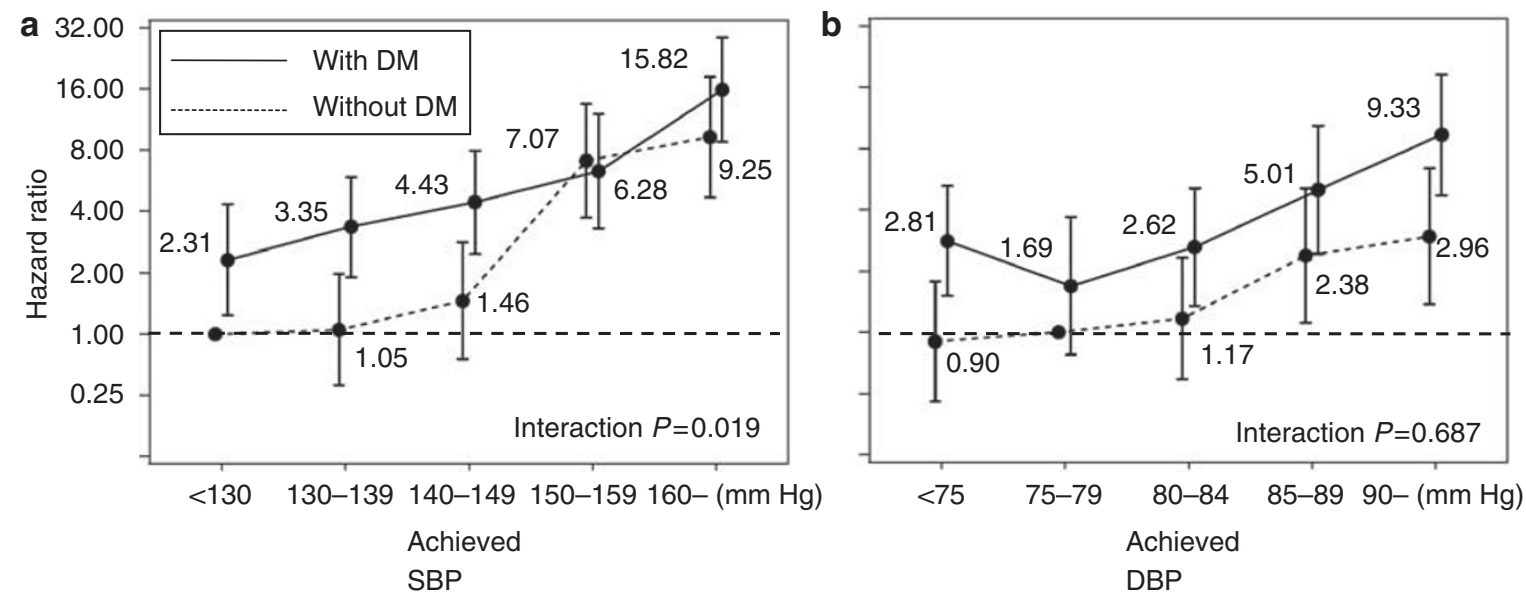

Figure 2 Adjusted relative risks of cardiovascular events and achieved BP in patients with/without DM. (a) The relationship between cardiovascular events and the achieved SBP and (b) the achieved DBP. A reference category was set at $<130 \mathrm{~mm} \mathrm{Hg}$ for SBP and at $75-79 \mathrm{~mm} \mathrm{Hg}$ for DBP in the subset of patients without DM.

set at $\leqslant 85$ and $\leqslant 90 \mathrm{~mm} \mathrm{Hg.} .^{15}$ The results of some other studies in hypertensive patients with DM have also suggested that greater benefit is obtained by setting the target $\mathrm{BP}$ at a lower level. ${ }^{16,17}$ Therefore, the Joint National Committee (JNC) $7^{5}$ and the European Society of Hypertension-European Society of Cardiology (ESH-ESC) Guidelines, ${ }^{6}$ as well as the guideline of JSH 2004, ${ }^{4}$ recommend $<130$ / $80 \mathrm{~mm} \mathrm{Hg}$ as the target optimal BP level in hypertensive patients with DM. Our study showed the results consistent with these recommendation for hypertensive patients with DM.

For hypertensive patients with CKD, a meta-analysis of 11 randomized controlled studies revealed that the incidence of end-stage renal failure and doubling of the serum creatinine were reduced by controlling SBP to $110-129 \mathrm{~mm} \mathrm{Hg}$ in hypertensive patients with urine protein excretion $>1.0 \mathrm{~g} \mathrm{day}^{-1}{ }^{18}$ Similar to hypertensive patients with DM, the guideline of JSH 2004 stipulates that the target BP for antihypertensive therapy is $<130 / 80 \mathrm{~mm} \mathrm{Hg}$ in hypertensive patients with CKD and $<125 / 75 \mathrm{~mm} \mathrm{Hg}$ in hypertensive patients with urinary protein loss exceeding $1.0 \mathrm{~g} \mathrm{day}^{-1}$. Our results are also consistent with the recommendation of the guideline of JSH 2004.

The first-line antihypertensive agents used in the CASE-J trial were candesartan and amlodipine. On the basis of the meta-analysis of the effects of treatment on the left ventricular mass in patients with 

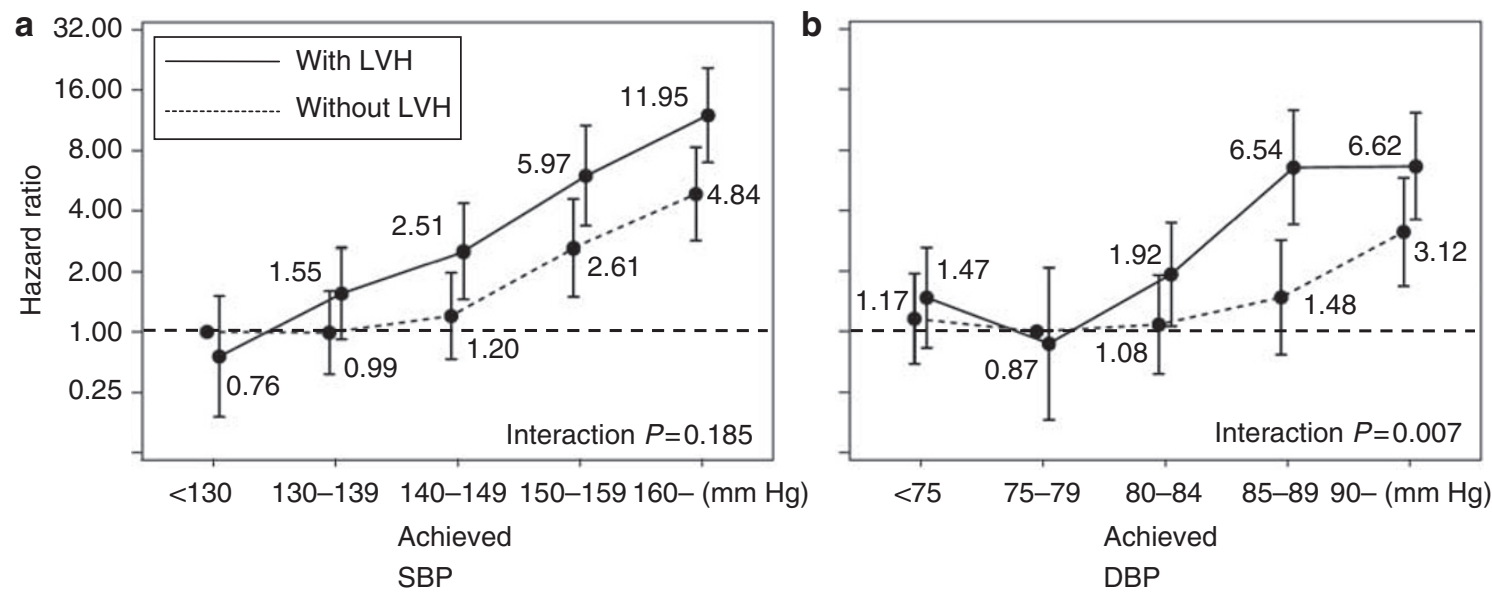

Figure 3 Adjusted relative risks of cardiovascular events and achieved BP in patients with/without LVH. (a) The relationship between cardiovascular events and the achieved SBP and (b) the achieved DBP. A reference category was set at $<130 \mathrm{~mm} \mathrm{Hg}$ for SBP and at $75-79 \mathrm{~mm} \mathrm{Hg}$ for DBP in the subset of patients without LVH.
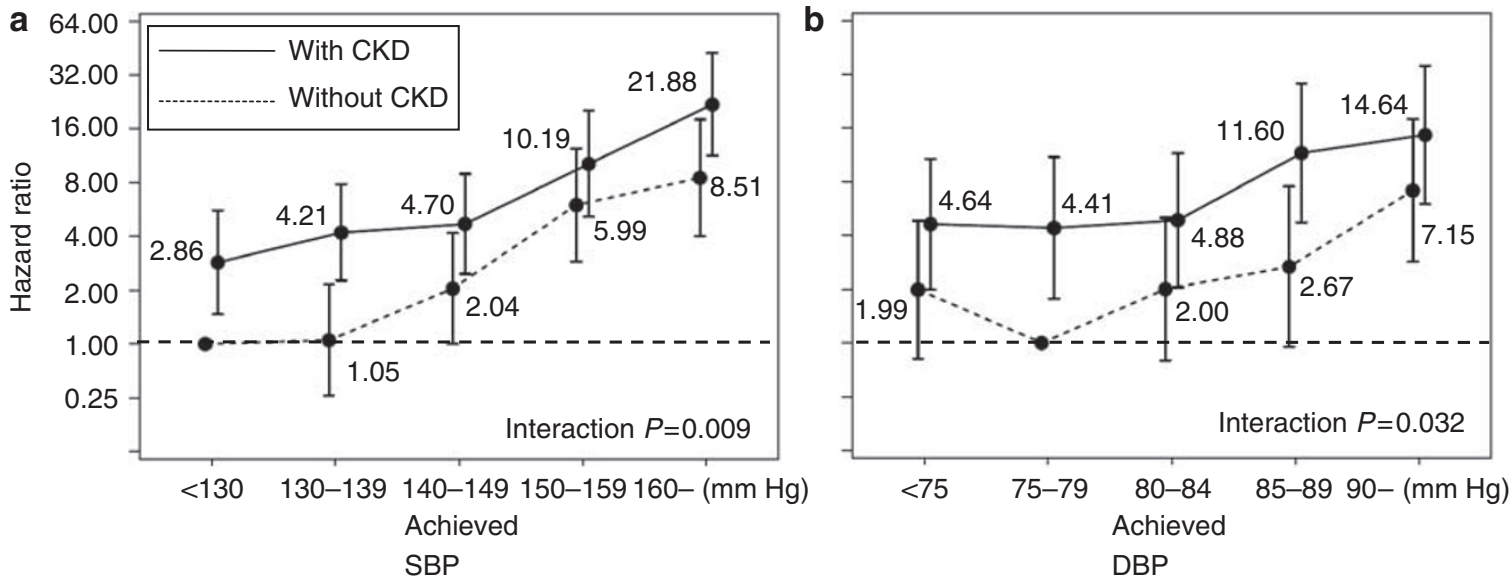

Figure 4 Adjusted relative risks of cardiovascular events and achieved BP in patients with/without CKD. (a) The relationship between cardiovascular events and the achieved SBP and (b) the achieved DBP. A reference category was set at $<130 \mathrm{~mm} \mathrm{Hg}$ for SBP and at $75-79 \mathrm{~mm} \mathrm{Hg}$ for DBP in the subset of patients without CKD.

essential hypertension, ${ }^{19}$ both agents have been recommended for hypertensive patients with LVH. It was found that strict BP control is more important for reducing the left ventricular mass than the class of antihypertensive agent by comparison of six antihypertensive agents. ${ }^{20}$ The most interesting point of this sub-analysis was that the risk of cardiovascular events in patients with $\mathrm{LVH}$, who could achieve SBP $<130 \mathrm{~mm} \mathrm{Hg}$ or DBP $75-79 \mathrm{~mm} \mathrm{Hg}$, was reduced to the same level as in those without LVH, but not in patients with DM or CKD. This indicates that hypertensive patients with these complications should be treated with strict BP control, and it is important for DM and CKD patients to receive not only antihypertensive therapy but also sufficient treatment for DM and CKD.

There are some limitations in this study. First, LVH was defined by criteria including electrocardiography, which is inferior in accuracy to echocardiography. Second, as this analysis was post hoc and patients were classified into several sub-groups, the population and the number of cardiovascular events in each group might not be enough to analyze the influence of achieved BP on these events. Third, we stratified by post-randomized variables; hence, this might introduce some bias whenever the association with outcome is confounded by more than just a baseline risk factor. Finally, as the CASE-J trial was not designed to determine the optimal BP levels in high-risk hypertensive patients, our results merely give an indication of the optimal BP levels when the patients received an antihypertensive treatment.

In conclusion, this sub-analysis of the CASE-J trial indicates that strict BP control leads to the risk reduction of cardiovascular events in hypertensive patients with DM, CKD or LVH. Further investigation in a large-scale clinical trial is needed to determine the optimal target BP for LVH patients.

\section{CONFLICT OF INTEREST}

Our conflict of interest is as follows: Drs T Ogihara, T Saruta, K Ueshima, K Takeda, J Higaki and K Nakao have received lecture fees from Takeda Pharmaceutical Co. and Pfizer Japan Inc. The other authors declare that they have no conflict of interest.

1 Fujishima M, Kiyohara Y, Kato I, Ohmura T, Iwamoto H, Nakayama K, Ohmori S, Yoshitake T. Diabetes and cardiovascular disease in a prospective population survey in Japan: The Hisayama Study. Diabetes 1996; 45 (Suppl 3): S14-S16. 
2 Epstein M, Sowers JR. Diabetes mellitus and hypertension. Hypertension 1992; 11: 69-76.

3 Grossman E, Messerli FH. Diabetic and hypertensive heart disease. Ann Intern Med 1996; 125: 304-310.

4 Japanese Society of Hypertension Guidelines Committee. Japanese Society of Hypertension Guideline for the Management of Hypertension (JSH2004). Hypertens Res 2006; 29: S1-105.

5 Chobanian AV, Bakris GL, Black HR, Cushman WC, Green LA, Izzo Jr JL, Jones DW, Materson BJ, Oparil S, Wright Jr JT, Roccella EJ, National Heart, Lung, and Blood Institute Joint National Committee on Prevention, Detection, Evaluation, and Treatment of High Blood Pressure; National High Blood Pressure Education Program Coordinating Committeelpar. The Seventh Report of the Joint National Committee on Prevention, Detection, Evaluation, and Treatment of High Blood Pressure: The JNC 7 Report. JAMA 2003; 289: 2560-2572.

6 Mancia G, De Backer G, Dominiczak A, Cifkova R, Fagard R, Germano G, Grassi G, Heagerty AM, Kjeldsen SE, Laurent S, Narkiewicz K, Ruilope L, Rynkiewicz A, Schmieder RE, Struijker Boudier HA, Zanchetti A, Vahanian A, Camm J, De Caterina R, Dean V, Dickstein K, Filippatos G, Funck-Brentano C, Hellemans I, Kristensen SD, McGregor K, Sechtem U, Silber S, Tendera M, Widimsky P, Zamorano JL, Kjeldsen SE, Erdine S, Narkiewicz K, Kiowski W, Agabiti-Rosei E, Ambrosioni E, Cifkova R, Dominiczak A, Fagard R, Heagerty AM, Laurent S, Lindholm LH, Mancia G, Manolis A, Nilsson PM, Redon J, Schmieder RE, Struijker-Boudier HA, Viigimaa M, Filippatos G, Adamopoulos S, Agabiti-Rosei E, Ambrosioni E, Bertomeu V, Clement D, Erdine S, Farsang C, Gaita D, Kiowski W, Lip G, Mallion JM, Manolis AJ, Nilsson PM, O'Brien E, Ponikowski P, Redon J, Ruschitzka F, Tamargo J, van Zwieten P, Viigimaa M, Waeber B, Williams B, Zamorano JL. 2007 Guidelines for the Management of Arterial Hypertension: The Task Force for the Management of Arterial Hypertension of the European Society of Hypertension (ESH) and of the European Society of Cardiology (ESC). Eur Heart J 2007; 28: 1462-1536.

7 Omata K, Kanazawa M, Sato T, Abe F, Saito T, Abe K. Therapeutic advantage of angiotensin converting enzyme inhibitors in chronic renal disease. Kidney Int 1996; 49 (Suppl 55): S57-S62.

8 Levy D, Garrison RJ, Savage DD, Kannel WB, Castelli WP. Prognostic implications of echocardiographically determined left ventricular mass in the Framingham Heart Study. N Engl J Med 1990; 322: 1561-1566.

9 Fukui T, Rahman M, Hayashi K, Takeda K, Higaki J, Sato T, Fukushima M, Sakamoto J, Morita S, Ogihara T, Fukiyama K, Fujishima M, Saruta T, CASE-J Study Group. Candesartan Antihypertensive Survival Evaluation in Japan (CASE-J) trial of cardiovascular events in high-risk hypertensive patients: rationale, design, and methods. Hypertens Res 2003; 26: 979-990.
10 Julius S, Kjeldsen SE, Weber M, Brunner HR, Ekman S, Hansson L, Hua T, Laragh J, McInnes GT, Mitchell L, Plat F, Schork A, Smith B, Zanchetti A, for the VALUE trial group. Outcomes in hypertensive patients at high cardiovascular risk treated with regimens based on valsartan or amlodipine: the VALUE randomised trial. Lancet 2004; 363: 2022-2031.

11 Ogihara T, Nakao K, Fukui T, Fukiyama K, Ueshima K, Oba K, Sato T, Saruta T, Candesartan Antihypertensive Survival Evaluation in Japan Trial Group. Effects of candesartan compared with amlodipine in hypertensive patients with high cardiovascular risks: Candesartan Antihypertensive Survival Evaluation in Japan trial. Hypertension 2008; 51: 393-398.

12 Japanese Society of Hypertension Guidelines Subcommittee for the Management of Hypertension. Guidelines for the management of hypertension for general practitioners. Hypertension Res 2001; 24: 613-634.

13 Cockroft DW, Gault MH. Prediction of creatinine clearance from serum creatinine. Nephron 1976; 16: 31-41.

14 Port S, Demer L, Jennrich R, Walter D, Garfinkel A. Systolic blood pressure and mortality. Lancet 2000; 355: 175-180.

15 Hansson L, Zanchetti A, Carruthers SG, Dahlöf B, Elmfeldt D, Julius S, Ménard J, Rahn $\mathrm{KH}$, Wedel H, Westerling S. Effects of intensive blood-pressure lowering and low-dose aspirin in patients with hypertension: principal results of the Hypertension Optimal Treatment (HOT) randomised trial. Lancet 1998; 351: 1755-1762.

16 UK Prospective Diabetes Study Group. Efficacy of atenolol and captoril in reducing risk of macrovascular complications in type 2 diabetes: UKPDS 39. BMJ 1998; 317 : 713-720.

17 Ravid M, Savin H, Jutrin I, Bental T, Katz B, Lishner M. Long-term stabilizing effect of angiotensin-converting enzyme inhibition on plasma creatinine and on proteinuria in normotensive type diabetic patients. Ann Intern Med 1993; 118: $577-581$.

18 Jafar TH, Stark PC, Schmid CH, Landa M, Maschio G, de Jong PE, de Zeeuw D, Shahinfar S, Toto R, Levey AS, , AIPRD Study Grouplpar. Progression of chronic kidney disease: the role of blood pressure control, proteinuria, and angiotensin-converting enzyme inhibition, a patient-level meta-analysis. Ann Intern Med 2003; 139: 244-252.

19 Klingbeil AU, Schneider M, Martus P, Messerli FH, Schmieder RE. A meta-analysis of the effects of treatment on left ventricular mass in essential hypertension. Am J Med 2003; 115: 41-46.

20 Gottdiener JS, Reda DJ, Massie BM, Materson BJ, Williams DW, Anderson RJ. Effect of single-drug therapy on reduction of left ventricular mass in mild to moderate hypertension: comparison of six antihypertensive agents. The Department of Veterans Affairs Cooperative Study Group on Antihypertensive Agents. Circulation 1997; 95: 2007-2014 